Criar Educação, Criciúma, v. 10, n¹, jan/jul 2021.- PPGE - UNESC - ISSN 2317-2452

\title{
O PEDAGOGO E OS MODELOS EDUCACIONAIS: PEDAGOGIA, ANDRAGOGIA E HEUTAGOGIA
}

\author{
Ingrides Leonel Araújo ${ }^{1}$ \\ Fabianne Cristina Lima da Silva ${ }^{2}$ \\ Aldenize Pinto de Melo do Nascimento ${ }^{3}$ \\ Kleber Mantovanelli Barbosa ${ }^{4}$
}

\section{RESUMO}

O Pedagogo é um profissional da Educação muito relevante para o desenvolvimento da formação humana e sua atuação se destaca, especialmente, nos modelos educacionais presentes na atualidade. O presente artigo tem por objetivo destacar a importância e as atribuições do profissional pedagogo no que se refere à sua atuação contemporânea nos modelos educacionais em questão: Pedagogia, Andragogia e Heutagogia. Essa produção foi resultado de discussões a partir de uma pesquisa de natureza bibliográfica e descritiva, se utilizando de referenciais de base e teóricos pertinentes a tal discussão e uma análise criteriosa sobre o conceito e a finalidade das Ciências de Ensino assim como a participação do Pedagogo em tais modelos. A pesquisa analisou os modelos de ensino propostos e a participação do pedagogo em cada um deles, realizou um paralelo comparativo e fez considerações em relação ao papel deste profissional. O pedagogo vem exercendo inúmeras atividades que o caracteriza como um profissional de função generalista e seu desafio, muitas vezes, é estar preparado para atender as variadas demandas deste setor, buscando a superação das limitações a fim de obter êxito em sua missão.

Palavras-chave: Educação - Pedagogia - Andragogia - Heutagogia

\section{THE PEDAGOGUE AND EDUCATIONAL MODELS: PEDAGOGY, ANDRAGOGY AND HEUTAGOGY}

\section{ABSTRACT}

The Pedagogue is an Education professional very relevant to the development of human

\footnotetext{
${ }^{1}$ Bacharel em Ciências Contábeis, Advogada, Pós-Graduada em Docência do Ensino Superior, PósGraduada em MBA em Gestão de Finanças, Controladoria e Auditoria. E-mail: ingrides.leonel@hotmail.com

${ }^{2}$ Graduada em Tecnólogo em Radiologia, Graduada em Pedagogia, Pós-graduação em Docência do Ensino Superior, Pós em Gestão e Auditoria no Sistema de Saúde. E-mail: fabiannecristinalima@gmail.com

3 Graduado em Filosofia, Mestre em Educação. Professora da SEDUC/AM. E-mail: aldenize.nascimento@seducam.pro.br

${ }^{4}$ Graduado em Administração de Empresas, Graduado em Ciências Contábeis, Pós-graduado em Contabilidade e Controladoria. Universitário em Ciências Contábeis, Diretor Administrativo Financeiro do ITEAM em Manaus/AM, professor universitário. E-mail: kleber@iteam.org.br
} 
education and his performance stands out, especially in the educational models present today. This article aims to highlight the importance and the attributions of the pedagogical professional with regard to his contemporary performance in the educational models in question: Pedagogy, Andragogy and Heutagogy. This production was the result of discussions based on a bibliographic and descriptive research, using basic and theoretical references relevant to such discussion and a careful analysis of the concept and purpose of Teaching Sciences as well as the participation of the Pedagogue in such models. The research analyzed the proposed teaching models and the participation of the pedagogue in each of them, made a comparative parallel and made considerations regarding the role of this professional. The pedagogue has been carrying out numerous activities that characterize him as a professional with a generalist function and his challenge is often to be prepared to meet the varied demands of this sector, seeking to overcome limitations in order to be successful in his mission.

Keywords: Education - Pedagogy - Andragogy - Heutagogy

\section{INTRODUÇÃO}

O pedagogo é aquele que constrói sua prática pedagógica na relação dialética entre conhecimento e ação, entre o saber fazer e o saber sobre o fazer e deve ser considerado um legítimo profissional da educação, desenvolvendo uma pedagogia coerente e articulada à sua realidade. Para o site Guia do Estudante (2019) o licenciado em Pedagogia entende dos princípios e métodos de ensino, da administração de escolas e da condução dos assuntos educacionais. Ele trabalha para garantir e melhorar a qualidade da educação.

O profissional tem dois grandes campos de atuação: a administração e a atuação como professor, de modo que pode tanto gerenciar e supervisionar o sistema de ensino e orientar professores e alunos quanto dar aulas (para a educação infantil e as cinco primeiras séries do Ensino Fundamental). Em órgãos do governo, o pedagogo estabelece e fiscaliza a legislação de ensino em todo o país. Em escolas, ele orienta e dirige os professores e verifica o cumprimento dos currículos e das diretrizes educacionais do país. Em sala de aula, leciona nas séries iniciais do Ensino Fundamental e acompanha e avalia o processo de aprendizagem e as aptidões de cada estudante. Além disso, o graduado está habilitado para trabalhar com a inclusão de pessoas com necessidades especiais ou educação a distância. 
Criar Educação, Criciúma, v. 9, no1, jan/jul 2021.- PPGE - UNESC - ISSN 2317-2452

O profissional de pedagogia tem ampliado significativamente seu campo de trabalho ao longo dos anos. A escola, que por muito tempo foi considerada o seu único espaço de atuação, hoje divide os profissionais com outras esferas que estão além da sala de aula. O pedagogo passou a ganhar espaço nos hospitais, ONGs, movimentos sociais e, inclusive, nas empresas (ALMEIDA; COSTA, 2012; LIBÂNEO, 2010).

O papel do pedagogo também varia conforme o estilo de abordagem pedagógica no processo de ensino aprendizagem, isto é conforme os modelos de gestão de aprendizagem, utilizada conforme os objetivos educacionais.

Os modelos educacionais, também reconhecidos como abordagens da aprendizagem, surgem a partir de observações e estudos do processo de ensino e aprendizagem nas variadas faixas etárias e em relação a metodologias empregadas pelos professores e verificados em termos de seus resultados pretendidos e alcançados. Abordagens educativas para crianças (Pedagogia) se diferenciam das realizadas para alunos adultos (Andragogia). E em resposta aos avanços das áreas do conhecimento, inclusive adas tecnologias disponíveis, cresce a demanda pela abordagem relacionada a Heutagogia que envolve a autonomia do aluno e sua evolução de forma personalizada.

Mediante todas as grandes essas transformações pelas quais a sociedade passa atualmente, a atuação do pedagogo passou a levar em conta, também, os modelos educacionais em questão, o que contribuiu para um incremento considerado de informação e a necessidade de uma formação profissional mais ampla e atualizada. Assim, a questão a ser respondida é: Qual o papel do pedagogo na gestão da aprendizagem relacionado aos modelos educacionais da aprendizagem? Desta forma, se faz necessário que o profissional de pedagogia saiba de forma clara as características individuais da Pedagogia, Andragogia e Heutagogia e a expectativa sobre seu desempenho profissional nos referidos modelos.

Portanto, o artigo em questão está organizado em revisão de literatura, metodologia adotada, bem como os resultados e considerações. Tem como objetivo realizar uma revisão bibliográfica que pretende: i. Apresentar os conceitos dos modelos de gestão de aprendizagem: Pedagogia, Andragogia e Heutagogia. ii. 
Analisar o papel do profissional em pedagogia dentro dos modelos de gestão de aprendizagem.

\section{REVISÃO DE LITERATURA}

\subsection{MODELOS DE GESTÃO DA APRENDIZAGEM}

\subsubsection{PEDAGOGIA: A ARTE DE ENSINAR CRIANÇAS E ADOLESCENTES}

A Pedagogia é uma ciência que estuda o ensino, começou a se desenvolver no século XIX. A pedagogia estuda diversos temas relacionados à educação, tem como objetivo principal a melhoria no processo de aprendizagem dos indivíduos, através da reflexão, sistematização e produção de conhecimentos, cita Meirieu (2002).

ao mesmo tempo, uma gramática dos saberes capaz de ordenar o caos dos conhecimentos humanos em um conjunto progressivamente acessível ao espírito do aluno e a experiência irredutível do limite do poder do homem sobre o homem, em outros termos, a experiência irredutível do sujeito (MEIRIEU, 2002, p. 124).

A palavra pedagogia vem do grego (pais, paidos = criança; agein $=$ conduzir; logos = tratado, ciência). $\mathrm{Na}$ antiga Grécia, eram chamados de pedagogos os escravos que acompanhavam as crianças que iam para a escola. Como escravo, ele era submisso à criança, mas tinha que fazer valer sua autoridade quando necessária. Por esse motivo, esses escravos desenvolveram grande habilidade no trato com as crianças. O professor, na pedagogia, sempre será o centro de toda e qualquer ação, por essa relação ser com crianças, ele que traça seus objetivos e o conteúdo ministrado.

Na pedagogia, o aluno é um dependente. É esperado pela sociedade que o professor assuma total responsabilidade pelo que deve ser aprendido, quando e como é pra ser aprendido e se foi aprendido. $\mathrm{O}$ que o aluno traz previamente é menos importante, é utilizado, mas muito mais como ponto de partida. O principal meio de aprendizado são as técnicas de transmissão do professor, o escritor de livros, o audiovisual de auxílio, as leituras atribuídas e apresentações. (CONAWAY, 2009).

Em relação à aptidão para o aprendizado, as pessoas estão prontas para 
aprender o que o meio social (especialmente escola), diz que devem aprender. A maioria das pessoas da mesma idade está pronta para aprender as mesmas coisas. Portanto o ensino deve ser organizado em um currículo padrão, como uma progressão relativamente uniforme para todos os alunos. Quanto à orientação para a aprendizagem, na Pedagogia os alunos veem a educação como aquisição de conhecimento em determinado assunto, mas entendem a aplicabilidade desse conhecimento apenas em sua vida futura. Assim, o currículo deve ser organizado em unidades de conhecimento (p.e. matérias), seguindo a lógica do sujeito (da história antiga para moderna, de problemas matemáticos simples para complexos). As pessoas são centradas no sujeito em sua orientação de aprendizado (NOGUEIRA, 2004).

Com o intuito de conceber a Pedagogia como Ciência da Educação, Libâneo (2001, p. 6) a define como "um campo de conhecimentos sobre a problemática educativa na sua totalidade e historicidade e, ao mesmo tempo, uma diretriz orientadora da ação educativa. ". Portanto, a pedagogia tem ocupação com o ato educativo, interessa pela prática educativa, perfazendo parte do cotidiano da atividade humana e da vida social do indivíduo.

A educação e seus desafios constituem o campo de atuação da Pedagogia, assim como as transformações oriundas do processo de ensino e aprendizagem. Seres humanos impactados em suas existências por meio de suas aprendizagens e relações estabelecias em sociedade. Portanto, tal processo ocorre pela comunicação, experiência acumulada, saberes e modos de agir acumulados pela humanidade e pela cultura transformada em patrimônio do ser humano. Resumindo Libâneo (2001, p. 10) diz que:

a Pedagogia, mediante conhecimentos científicos, filosóficos e técnicoprofissionais, investiga a realidade educacional em transformação, para explicitar objetivos e processos de intervenção metodológica e organizativa referentes à transmissão/assimilação de saberes e modos de ação. Ela visa o entendimento, global e intencionalmente dirigido, dos problemas educativos e, para isso, recorre aos aportes teóricos providos pelas demais ciências da educação. 
A Sociologia, a Psicologia, a Economia, entre outras, tem se ocupado com os problemas educativos, abordando-os segundo o referencial teórico construídos por estas ciências. Entretanto, "é a Pedagogia que pode postular o educativo, propriamente dito, e ser ciência integradora dos aportes das demais áreas. Portanto a Pedagogia é a ciência que tem a educação como objeto de estudo. Isto não quer dizer, todavia, que ela, por isso, passa ocupar lugar hierarquicamente superior às demais" (LIBÂNEO, 1996, p. 118), cabendo-lhe ocupar o seu devido lugar como Ciência da Educação.

Para Saviani (2001):

na verdade o conceito de Pedagogia se reporta a uma teoria que se estrutura a partir e em função da prática educativa. A pedagogia, como teoria da educação, busca equacionar, de alguma maneira, o problema da relação educador-educando, de modo geral, ou, no caso específico da escola, a relação professor-aluno, orientando o processo de ensino e aprendizagem (SAVIANI, 2007, p. 102).

Sendo assim, é o pedagogo, que facilita a transformação da informação em saber por meio de uma prática relacional e da ação do professor na sala de aula, organizando situações pedagógicas para o aprendiz, ou seja, formas de comunicação que favoreçam a aprendizagem dos alunos. De acordo com GADOTTI (2000):

os educadores, numa visão emancipadora, não só transformam a informação em conhecimento e em consciência crítica, mas também formam pessoas. Diante dos falsos pregadores da palavra, dos marketeiros, eles são os verdadeiros "amantes da sabedoria", os filósofos de que nos falava Sócrates. Eles fazem fluir o saber (não o dado, a informação e o puro conhecimento), porque constroem sentido para a vida das pessoas e para a humanidade e buscam, juntos, um mundo mais justo, mas produtivo e mais saudável para todos. Por isso eles são imprescindíveis. (GADOTTI, M. Perspectivas atuais da educação, 2000)

Na Pedagogia, o educador é um mediador do conhecimento diante do aluno que é o sujeito da sua própria formação. Ele precisa construir conhecimento a partir do que faz e, para isso, também precisa ser curioso, buscar sentido para o que faz e apontar novos sentidos para o fazer dos seus alunos.

\subsubsection{ANDRAGOGIA: A ARTE DE ENSINAR JOVENS E ADULTOS}

Andragogia, termo popularizado por Malcon Knowles (1970) com a publicação 
de seu livro The modern pratctice of adult education, no qual o autor apresenta 0 conceito como a arte e a ciência de orientar os adultos a aprender (GIL, 2011, p.12). Significa também, um conjunto de princípios de aprendizagem de adultos que se aplicam a todas as situações que envolvem este discente.

Assim, faz-se importante e urgente ampliarmos o que conhecemos sobre Andragogia pois "assim como são diferentes as formas de aprender, devem ser diferentes também as formas de ensinar" (VEIGA, 2012, p. 26). Rogers entende que uma das formas mais eficientes de aprender é "confessar as próprias dúvidas, procurar esclarecer os próprios enigmas, com o propósito de compreender melhor, o significado real da própria experiência" (ROGERS, 2011, p. 319). A forma como os adultos aprendem são diferentes das crianças sendo necessário que aprendamos os diferentes métodos e práticas andragógicas.

A Andragogia é uma ciência que estuda a educação para adultos com o objetivo de buscar uma aprendizagem verdadeira para o desenvolvimento de habilidades e conhecimento do discente adulto, pois eles aprendem com mais facilidade em ambientes informais, confortáveis, flexíveis e sem ameaças. Essa ciência tem por objetivo ajudar no desenvolvimento e possui características específicas. É a disciplina educativa que tenta compreender o adulto a partir de todos os componentes humanos, quer dizer, como um ser biológico e social (MÁRQUEZ, 1998 apud MARQUES, 2007).

A palavra "Andragogia" vem do grego andros que significa adulto, e agogôs, que significa educar, ou seja, a arte de ensinar jovens e adultos. Segundo Bellan (2005, p.20), "a Andragogia é a ciência que estuda como os adultos aprendem". Essa mesma autora relata que foi o educador alemão Alexander Kapp em 1833, que fora o pioneiro a usar tal nomenclatura. A Andragogia surgiu da confrontação à Pedagogia que é direcionada à arte de ensinar crianças e adolescentes. Da pedagogia que surgiram às críticas, a busca de superação e melhorias no processo de ensinoaprendizagem por parte dos idealizadores da Andragogia, tais críticas seriam: ensino muito diretivo, centrado na figura do professor, baseado em conhecimentos direcionados por este, desprezando a experiência e vivência do aluno.

A experiência do aprendiz tem pouco valor como fonte de aprendizagem; a 
experiência considerada é a do professor, a do livro didático, a do escritor e a dos recursos audiovisuais. Por isso, técnicas de transmissão - leituras, dever de casa etc., são a essência da metodologia pedagógica. (...) Aprendizes têm a orientação de aprendizagem voltada para disciplinas; eles veem o aprendizado como uma aquisição de conteúdo. Por isso as experiências de aprendizagem são organizadas de acordo com a lógica de conteúdo programático. (OLIVEIRA, 1999, p.27).

Madeira (1999) comenta as limitações da pedagogia responsáveis pela emergência da Andragogia:

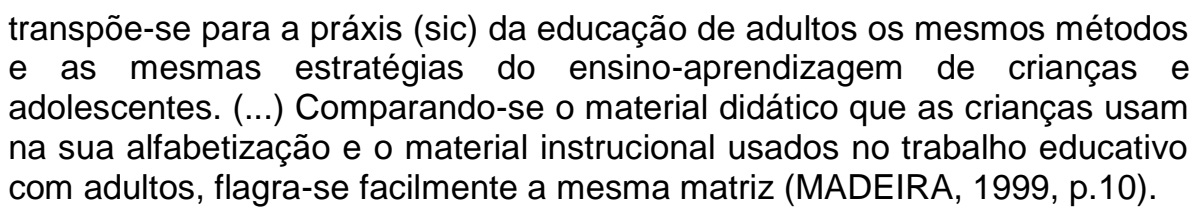

Notam-se com clareza as críticas à pedagogia, afirmando que o modelo de ensino aprendizagem embutido na pedagogia possui na maioria das vezes a mesma matriz. De acordo com Gomes, Pezzi e Bárcia (2006), os princípios da Andragogia e as teorias que sinalizam uma pedagogia voltada para o aluno, estão trazendo maiores contribuições no trabalho com adultos.

Aprendizagem baseada em Andragogia é um processo normal de maturação em que uma pessoa sai da dependência para uma crescente auto direção do conhecimento, mas em diferentes níveis, para diferentes pessoas e diferentes aspectos da vida. Aqui os professores têm a responsabilidade de incentivar e proporcionar essa mudança, embora os alunos possam ser dependentes em situações transitórias, como no exemplo citado anteriormente.

Quanto ao papel do aluno na Andragogia, conforme as pessoas crescem e se desenvolvem, acumulam experiências que se tornam recursos de aprendizagem para si e para os outros. Além disso, adultos atribuem maior valor ao que aprendem por meio de experiências do que o conhecimento adquirido passivamente. Portanto, aqui as técnicas principais de educação são as experiências em laboratório, simulação de solução de problemas, discussão e experiência de campo (CONAWAY, 2009).

Quanto à aptidão para o aprendizado, as pessoas se tornam prontas quando 
sentem necessidade de aprender alguma coisa, com a finalidade de lidar mais satisfatoriamente com problemas reais e cotidianos. O educador deve criar situações e fornecer ferramentas para que o aprendiz descubra seu "preciso saber". Os programas de aprendizado devem ser organizados conforme as aplicações práticas, e sequenciados de acordo com a prontidão do aluno para aprender (HOLTON; SWANSON, 2001).

$\mathrm{Na}$ orientação para a aprendizagem, os alunos veem a educação como um processo de desenvolvimento de competências para alcançar seu pleno potencial na vida. Querem ser capazes de aplicar qualquer conhecimento e habilidade que adquiriram hoje para viverem melhor amanhã. De acordo com isso, as experiências de aprendizado devem ser organizadas em métodos de desenvolvimento de competências, já que os adultos são centrados na melhora de sua competência em sua orientação para o aprendizado.

A Andragogia baseia-se em seis princípios fundamentais: necessidade, autoconhecimento, experiência, orientação, prontidão e motivação.

\section{- NECESSIDADE DE CONHECER}

Os alunos adultos sabem da sua necessidade de conhecimento, assim como de colocar em prática o conhecimento adquirido, necessitam saber por que aprender algo. Surgindo assim os questionamentos: "O que é que eu ganho com isto que quer me ensinar? " E "Por que preciso?".

Adultos precisam entender porque precisam aprender sobre determinado assunto antes de aprendê-lo. Isso é importante na medida em que o indivíduo racionaliza o que está sendo explicado, e transfere esse conhecimento para aplicações práticas importantes para sua vida. E perguntar ao aluno sobre o significado atribuído por ele ao que foi exposto, faz com que professor e aluno detectem juntos, onde mais falta conhecimento, ou se este está de acordo com os objetivos (CHESBRO, DAVIS, 2002).

\section{- $\quad$ AUTOCONCEITO DE APRENDIZ}


Os alunos adultos precisam entender como podem ser independentes e alunos ao mesmo tempo, e por serem responsáveis por si próprios, tem muitas dificuldades em que outros the digam o que tenham ou não o que fazer. Surgindo assim os questionamentos: "Como posso participar? "E "Posso decidir meus caminhos? ".

$O$ autoconceito dos adultos é fortemente dependente de um movimento para a auto direção. Como se espera que adultos sejam indivíduos independentes em muitos aspectos de suas vidas, na educação não pode ser diferente. Adultos devem, conforme sua capacidade, sair da condição de dependentes do professor, para então gerir seu próprio aprendizado. Identificar se o aluno prefere aulas mais técnicas ou mais lúdicas, ou ensiná-lo onde buscar informação quando tiver dúvidas fora do momento da aula, são exemplos da aplicação desse pressuposto (VOGT, 2005).

\section{- O PAPEL DA EXPERIÊNCIA}

Os alunos adultos têm uma bagagem muito maior e mais variada de experiências, que consequentemente se tornam a base do seu aprendizado, assim como também podem ocasionar preconceitos e hábitos costumeiros que dificultam e interferem na sua aprendizagem. Surgindo assim os questionamentos: "Como isso se relaciona com o que eu já sei? " E "Como posso usar minha experiência? ".

\section{- ORIENTAÇÃO PARA APRENDIZAGEM}

Os alunos adultos têm a orientação da aprendizagem focada na vida, nos problemas que vivenciam, as visões de futuro e tempo do adulto levam-no a favorecer a aprendizagem daquilo que possa ter aplicação imediata e centrada em áreas de conhecimentos já vistos. Surgindo assim o questionamento: "Eu estou aprendendo matérias ou ganhando ferramentas? ".

As experiências a priori do aprendiz são um recurso rico para o aprendizado. Além de levar em conta as preferências dos alunos, como citado anteriormente, o facilitador deve levar em conta as experiências de vida que o aluno traz sobre o objeto de ensino, e não só o que já foi estudado ou não. Os adultos precisam que se atribua valor a suas experiências prévias, sob pena de se sentir rejeitado como gente. Isso se 
agrava quando se trata de indivíduos com pouco estudo, pois o que mais essa pessoa tem do que suas experiências? (COSTA, 2005).

\section{- PRONTIDÃO PARA APRENDER}

Os alunos adultos têm prontidão de aprender as coisas que precisam saber para enfrentar no seu dia a dia, ou seja, esse aluno tem muito mais interesse em aprender assuntos relacionados às situações reais de sua vida. Surgindo assim os questionamentos: "Qual problema que vou resolver agora com isso que você quer que eu aprenda? " E "Posso aplicar à minha realidade hoje? ".

\section{- MOTIVAÇÃO}

Os alunos adultos respondem melhor aos fatores motivacionais internos, como o desejo de ter maior satisfação no trabalho, autoestima e qualidade de vida, do que aos externos como melhores empregos, promoções e salários mais altos. Baseada na própria vontade de crescimento do adulto (motivação interna) e não em estímulos externos como vindos de outras pessoas, como notas de professores entre outros. Surgindo assim o questionamento: "Dedicar-me a isto vai resultar em mais satisfação ou melhorar a minha vida?".

A motivação interna (intrínseca) é aquela que leva o indivíduo a procurar alguma atividade por vontade própria (LOPES, 2011). Ora, se o indivíduo procura uma atividade por vontade própria, e tem interesse de melhorar algum aspecto da própria vida, é justo que o professor construa junto com o aluno o plano de ensino, seja qual for 0 ambiente onde $o$ adulto busca $o$ aprendizado.

O profissional pedagogo, ao atuar no modelo de aprendizagem voltado para pessoas adultas, passa a considerar as experiências e vivências dos alunos na construção do seu método de ensino, seja ele EJA, Educação Profissional ou até mesmo na integração e gestão dos sistemas de ensino.

\subsubsection{HEUTAGOGIA: A ARTE DA AUTONOMIA DO APRENDIZ}

A Heutagogia é o estudo da aprendizagem autodeterminada. O conceito foi 
criado pelos teóricos Stewart Hase e Chris Kenyon, em 2000, termo derivado do grego onde heutos significa auto, próprio e agogus guiar. Consistiu em uma tentativa de desafiar concepções sobre ensino e aprendizagem centradas no professor e na necessidade de "compartilhar conhecimento". No artigo "Da Andragogia à Heutagogia" (2000), os autores afirmam que a heutagogia olha para um futuro em que saber aprender será uma habilidade fundamental, dado o ritmo da inovação e a estrutura em mudança das comunidades e dos locais de trabalho.

A heutagogia também tem sido bastante disseminada graças ao expressivo crescimento de cursos de Educação a Distância (EAD). O papel do professor é evidentemente diferente do exercido em cursos presenciais, uma vez que o aluno é quem precisa tomar a iniciativa de ir atrás do conhecimento, não havendo um contexto imediato que o obrigue a isso; nesse caso, o professor atua como um mediador ou facilitador do processo de aprendizagem. A diferença principal de uma abordagem baseada na heutagogia é que fica a cargo do aluno escolher o conteúdo que vai aprender; cada trajetória de aprendizagem é única de acordo com escolhas, motivações e objetivos de cada pessoa.

A Heutagogia é uma ciência que proporciona uma grande independência e autonomia do aluno, podendo ele assim escolher o que, e o como aprender em concordância com suas metas e objetos provisionados. É uma área de recente visão sobre os fatores de sucesso na construção do conhecimento. O papel do professor é instruir atuando como mediador, orientando as escolhas dos aprendizes e disponibilizando ferramentas adequadas para a eficiência e eficácia desse processo. E assim, se dá a brilhante fase da aprendizagem autodeterminada, em que cada um se afirma, sendo detentor do seu próprio processo de aprendizagem (CALDEIRA, 2012).

De acordo com Fredric Litto, presidente da Associação Brasileira de Educação a Distância (ABED):

já passamos pela Pedagogia, método que o professor determina o que e como aprender. Estamos tentando utilizar a Andragogia, teoria na qual é o professor quem determina o que, mas é o aluno quem determina como. Mas hoje, já temos de ingressar na Heutagogia, método pelo qual é o aprendiz quem fixa o que e como aprender (LITTO, 2009). 
A ênfase está focada muito mais na aprendizagem que no ensino. Refere-se a um conceito que "reconhece as experiências cotidianas como fonte de saber e incorpora a auto direção da aprendizagem com foco nas experiências". "Como aprender a aprender"? A proposta é que conteúdos e modelos de oferta sejam pensados, objetivando a habilidade de aprender e o processo de adquirir conhecimento. (SANTOS, 2008).

Nestes termos, pode-se afirmar que "ensinar" é prover os recursos, mas é aquele que aprende é quem direciona sua aprendizagem. Esses discentes podem acessar leituras e questões em outras fontes, determinar o que é interessante e o que é relevante para eles e negociar tarefas de estudo e avaliação. Orientar ou "ensinar" significa pensar mais no processo que no conteúdo, buscando assim um sentido no mundo de quem aprende e não no de quem ensina. É tudo estímulo, pois aprender é inerente ao indivíduo e é um processo que ocorre dentro e fora dele, ou seja, com esse conhecimento o indivíduo transforma suas ações e reações ao mundo. Toda e qualquer experiência é válida, pois aprendizagem não é um processo linear, mas sim aleatório e não necessariamente segue uma ordem específica.

Litto também traçou o perfil de um estudante à distância. Segundo ele, "a EAD não é para qualquer um. O aluno que depende de cobrança ou elogios só serve para o presencial. Para utilizar a EAD é preciso ser motivado e autodisciplinado". A Heutagogia, como a Andragogia, aceita e reconhece as experiências do dia-a-dia como fonte de aprendizado, acessadas de forma informal (estudos independentes) ou por conexão com colegas de profissão, tutores ou mentores.

Esta forma de aprendizagem também tem sua importância no que diz respeito à assimilação de novos conhecimentos para o desenvolvimento de novas habilidades, exigência de um mundo em constante mutação. Torna este processo mais rápido para se adquirir o conhecimento e, ao mesmo tempo, mais flexível, porque será o aprendiz que vai determinar qual a parcela de tempo que ele usará para isso.

O profissional pedagogo, ao atuar no modelo de aprendizagem citado, passa a ser um mediador e facilitador no processo de ensino e aprendizagem, tendo ciência 
Criar Educação, Criciúma, v. 9, no1, jan/jul 2021.- PPGE - UNESC - ISSN 2317-2452

de que o aluno possui autonomia e liberdade para estabelecer seus próprios objetivos e definir sua trajetória, cedendo espaço para um total protagonismo por parte do aluno.

\section{METODOLOGIA}

Como procedimento metodológico de vertente qualitativa, foi adotada a pesquisa bibliográfica e a análise de documentos normativos e legais, respaldadas em processo de fundamentação da temática, mais especificamente nos estudos dos teóricos: Libâneo (2001b; 2006), Silva (1999) e Franco (2002). Para Lakatos; Marconi (1993), a pesquisa bibliográfica abrange toda a bibliografia já tornada pública em relação ao termo de estudo. A técnica utilizada foi a bibliográfica, buscando dados atualizados. Trata-se de um estudo bibliográfico com ênfase na pesquisa descritiva.

A pesquisa descritiva é aquela que o pesquisador direciona sua observação aos fenômenos do mundo físico e humano sem intervir nos mesmos, por meio de fatos as quais são observados, registrados, analisados, classificados e interpretados. Quanto à pesquisa bibliográfica, procura explicar um problema a partir de referências teóricas publicadas, pode ser realizada independentemente, ou como parte de outros tipos de pesquisa.

\section{RESULTADOS E DISCUSSÕES}

\subsection{PEDAGOGIA}

Na Pedagogia é o Professor quem determina todo o conteúdo a ser aprendido e de que forma será aprendido. O pedagogo, enquanto profissional da educação, se encontra no centro do processo de ensino e aprendizagem e detém todos os meios, técnicas e métodos para gerencial os resultados.

\section{QUESTIONAMENTOS PEDAGOGIA}


Criar Educação, Criciúma, v. 9, nº1, jan/jul 2021 -- PPGE - UNESC - ISSN 2317-2452

protagonismo do aluno. De certa forma, se abre para a possibilidade de aprender em conjunto e de acompanhar de perto o desenvolvimento do aprendiz.

Quadro 03: Questionamento na Heutagogia

\begin{tabular}{|c|c|c|c|}
\hline QUESTIONAMENTOS & PEDAGOGIA & ANDRAGOGIA & HEUTAGOGIA \\
\hline $\begin{array}{c}\text { Quem determina o que } \\
\text { deve ser aprendido? }\end{array}$ & Professor & Facilitador & Aprendiz \\
\hline $\begin{array}{c}\text { Quem determina como } \\
\text { deve ser aprendido? }\end{array}$ & Professor & Aprendiz & Aprendiz \\
\hline
\end{tabular}

Fonte: Fava Consulting

Portanto, a seguir apresenta-se o quadro explicativo, sobre as ciências da educação, após o levantamento e discussão, entre Pedagogia, Andragogia e Heutagogia:

Quadro 04: Ciências da Educação

\begin{tabular}{|c|c|c|c|}
\hline & PEDAGOGIA & ANDRAGOGIA & HEUTAGOGIA \\
\hline METODOLOGIA & $\begin{array}{l}\text { Fundamentada nos } \\
\text { exercícios, na } \\
\text { repetição de } \\
\text { conceitos ou } \\
\text { fórmulas e na } \\
\text { memorização, } \\
\text { visando disciplinar } \\
\text { a mente e formar } \\
\text { hábitos. }\end{array}$ & $\begin{array}{l}\text { Fundamentada em } \\
\text { eixos articuladores } \\
\text { da motivação e da } \\
\text { experiência dos } \\
\text { aprendizes adultos. }\end{array}$ & $\begin{array}{c}\text { Fundamentada no } \\
\text { desempenho } \\
\text { individual e seus } \\
\text { processos de } \\
\text { aprendizagem } \\
\text { autodeterminada. }\end{array}$ \\
\hline ALUNO & Dependentes & $\begin{array}{l}\text { Independentes e } \\
\text { auto direcionados. }\end{array}$ & $\begin{array}{c}\text { Independente e } \\
\text { auto aprendizados. }\end{array}$ \\
\hline AVALIAÇÃO & $\begin{array}{l}\text { Conduzida e } \\
\text { direcionada pelo } \\
\text { professor. }\end{array}$ & $\begin{array}{l}\text { Acompanhada pelo } \\
\text { facilitador e } \\
\text { determinada pelo } \\
\text { aprendiz adulto. }\end{array}$ & $\begin{array}{c}\text { Determinada e } \\
\text { executada pela } \\
\text { iniciativa do } \\
\text { próprio aluno. }\end{array}$ \\
\hline MOTIVAÇÃO & $\begin{array}{l}\text { Extrínseca } \\
\text { (recompensa, } \\
\text { competição). }\end{array}$ & $\begin{array}{c}\text { Intrínseca } \\
\text { (entusiasmo com o } \\
\text { aprendizado). }\end{array}$ & $\begin{array}{l}\text { De forma } \\
\text { característica e } \\
\text { pessoal. }\end{array}$ \\
\hline
\end{tabular}




\section{(2)

Criar Educação, Criciúma, v. 9, nº1, jan/jul 2021 - PPGE - UNESC - ISSN 2317-2452

\begin{tabular}{|c|c|c|c|}
\hline $\begin{array}{c}\text { FORMA DE } \\
\text { APRENDIZAGEM }\end{array}$ & $\begin{array}{c}\text { Por aulas e leituras } \\
\text { indicadas. }\end{array}$ & $\begin{array}{c}\text { Por } \\
\text { questionamentos } \\
\text { indagadores, } \\
\text { experiências e } \\
\text { estudos } \\
\text { independentes. }\end{array}$ & $\begin{array}{c}\text { Por novas } \\
\text { tecnologias, vídeo- } \\
\text { aulas e apostilas } \\
\text { impressas e } \\
\text { digitais. }\end{array}$ \\
\hline AMBIENTE & $\begin{array}{c}\text { Formal e } \\
\text { tradicional. }\end{array}$ & $\begin{array}{l}\text { Informal, com } \\
\text { respeito mútuo e } \\
\text { cooperação. }\end{array}$ & $\begin{array}{l}\text { Virtuais, como } \\
\text { internet, } \\
\text { aplicações } \\
\text { multimídias. }\end{array}$ \\
\hline
\end{tabular}

Fonte: Própria

\subsection{ANALOGIA}

Ao analisar os modelos de aprendizagem, foi feita uma analogia entre os tipos e a atuação do profissional pedagogo. Desta forma, foi possível reconhecer a diversidade de ações e os desafios encarados pelo pedagogo para atender as demandas do sistema educacional nos tempos atuais.

\section{Quadro 05: Modelos x atuação do pedagogo}

\begin{tabular}{|c|c|c|c|c|}
\hline & PEDAGOGIA & NDRAGOGIA & HEUTAGOGIA & PAPEL DO PEDAGOGO \\
\hline $\begin{array}{l}\text { METOD } \\
\text { OLOGIA }\end{array}$ & $\begin{array}{l}\text { Fundamentad } \\
\text { a nos } \\
\text { exercícios, na } \\
\text { repetição de } \\
\text { conceitos ou } \\
\text { fórmulas e na } \\
\text { memorização, } \\
\text { visando } \\
\text { disciplinar a } \\
\text { mente e } \\
\text { formar hábitos. }\end{array}$ & $\begin{array}{l}\text { Fundamentada } \\
\text { em eixos } \\
\text { articuladores da } \\
\text { motivação e da } \\
\text { experiência dos } \\
\text { aprendizes } \\
\text { adultos. }\end{array}$ & $\begin{array}{l}\text { Fundamentada } \\
\text { no desempenho } \\
\text { individual e seus } \\
\text { processos de } \\
\text { aprendizagem } \\
\text { autodeterminad } \\
\text { a. }\end{array}$ & $\begin{array}{l}\text { PEDAGOGIA: } \\
\text { Escolhe sozinho qual metodologia a } \\
\text { ser usada conforme o que julgar } \\
\text { adequado ao aluno. } \\
\text { ANDRAGOGIA: } \\
\text { Coopera com a escolha do tipo de } \\
\text { metodologia a ser utilizada conforme a } \\
\text { necessidade do aluno. } \\
\text { HEUTAGOGIA: A atuação do } \\
\text { pedagogo se restringe a realizar } \\
\text { suporte necessário quando solicitado. }\end{array}$ \\
\hline ALUNO & Dependentes & $\begin{array}{l}\text { Independentes } \\
\text { e auto } \\
\text { direcionados. }\end{array}$ & $\begin{array}{l}\text { Independente e } \\
\text { auto } \\
\text { aprendizados. }\end{array}$ & $\begin{array}{l}\text { PEDAGOGIA: } \\
\text { Total dependência do aluno em relação } \\
\text { ao pedagogo. } \\
\text { ANDRAGOGIA: O pedagogo age como } \\
\text { mediador e facilitador. }\end{array}$ \\
\hline
\end{tabular}


CRIAR EDUCAÇÃO

Revista do Programa de Pós-Graduação em Educação - UNESC

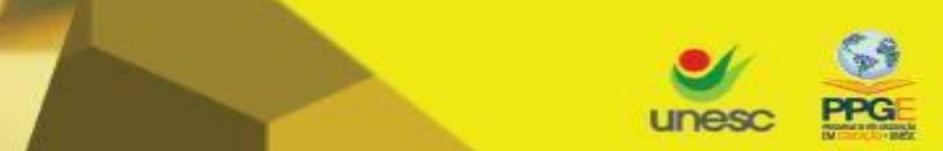

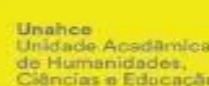
ver

Criar Educação, Criciúma, v. 9, ํo1, jan/jul 2021 .- PPGE - UNESC - ISSN 2317-2452

\begin{tabular}{|c|c|c|c|c|}
\hline & & & & $\begin{array}{l}\text { HEUTAGOGIA: Estudante totalmente } \\
\text { autônomo. A atuação do pedagogo se } \\
\text { restringe a realizar suporte necessário } \\
\text { quando solicitado. }\end{array}$ \\
\hline $\begin{array}{l}\text { AVALIA } \\
\text { ÇÃO }\end{array}$ & $\begin{array}{l}\text { Conduzida e } \\
\text { direcionada } \\
\text { pelo professor. }\end{array}$ & $\begin{array}{l}\text { Acompanhada } \\
\text { pelo facilitador e } \\
\text { determinada } \\
\text { pelo aprendiz } \\
\text { adulto. }\end{array}$ & $\begin{array}{c}\text { Determinada e } \\
\text { executada pela } \\
\text { iniciativa do } \\
\text { próprio aluno. }\end{array}$ & $\begin{array}{c}\text { PEDAGOGIA: } \\
\text { Dentro dos critérios do pedagogo } \\
\text { focado na mensuração de retenção de } \\
\text { conteúdo. } \\
\text { ANDRAGOGIA: } \\
\text { O pedagogo age como facilitador para } \\
\text { verificação da qualidade da escolha } \\
\text { dos pontos selecionados pelo aluno. } \\
\text { HEUTAGOGIA: A atuação do } \\
\text { pedagogo se restringe a realizar } \\
\text { suporte necessário quando solicitado. }\end{array}$ \\
\hline $\begin{array}{l}\text { MOTIVA } \\
\text { ÇÃO }\end{array}$ & $\begin{array}{l}\text { Extrínseca } \\
\text { (recompensa, } \\
\text { competição). }\end{array}$ & $\begin{array}{l}\text { Intrínseca } \\
\text { (entusiasmo } \\
\quad \text { com o } \\
\text { aprendizado). }\end{array}$ & $\begin{array}{c}\text { De forma } \\
\text { característica e } \\
\text { pessoal. }\end{array}$ & $\begin{array}{l}\text { PEDAGOGIA: O pedagogo trabalha no } \\
\text { estilo estimulo/resposta. } \\
\text { ANDRAGOGIA: } \\
\text { O pedagogo agira como cooperador } \\
\text { para a automotivação do aluno a partir } \\
\text { do alcance de seus objetivos. } \\
\text { HEUTAGOGIA: } \\
\text { A atuação do pedagogo se restringe a } \\
\text { realizar suporte necessário quando } \\
\text { solicitado. }\end{array}$ \\
\hline $\begin{array}{l}\text { FORMA } \\
\text { DE } \\
\text { APREN } \\
\text { DIZAGE } \\
\text { M }\end{array}$ & $\begin{array}{l}\text { Por aulas e } \\
\text { leituras } \\
\text { indicadas. }\end{array}$ & $\begin{array}{c}\text { Por } \\
\text { questionamento } \\
\text { s indagadores, } \\
\text { experiências e } \\
\text { estudos } \\
\text { independentes. }\end{array}$ & $\begin{array}{l}\text { Por novas } \\
\text { tecnologias, } \\
\text { vídeo-aulas e } \\
\text { apostilas } \\
\text { impressas e } \\
\text { digitais. }\end{array}$ & $\begin{array}{c}\text { PEDAGOGIA: } \\
\text { Sob total orientação do pedagogo, } \\
\text { podendo ou não usar metodologias } \\
\text { ativas ou tradicionais. } \\
\text { ANDRAGOGIA: } \\
\text { O pedagogo age como parceiro no } \\
\text { processo de aprendizagem do aluno, } \\
\text { cooperando quando necessário com } \\
\text { orientações. } \\
\text { HEUTAGOGIA: }\end{array}$ \\
\hline
\end{tabular}




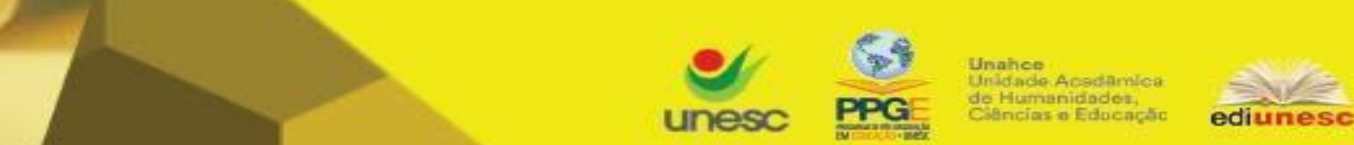

Criar Educação, Criciúma, v. 9, nº1, jan/jul 2021 - PPGE - UNESC - ISSN 2317-2452

\begin{tabular}{|c|c|c|c|c|}
\hline & & & & $\begin{array}{c}\text { A atuação do pedagogo se restringe a } \\
\text { realizar suporte necessário quando } \\
\text { solicitado. }\end{array}$ \\
\hline $\begin{array}{c}\text { AMBIEN } \\
\text { TE }\end{array}$ & $\begin{array}{c}\text { Formal e } \\
\text { tradicional. }\end{array}$ & $\begin{array}{l}\text { Informal, com } \\
\text { respeito mútuo } \\
\text { e cooperação. }\end{array}$ & $\begin{array}{l}\text { Virtuais, como } \\
\text { internet, } \\
\text { aplicações } \\
\text { multimídias. }\end{array}$ & $\begin{array}{c}\text { PEDAGOGIA: Ambiente de } \\
\text { aprendizagem conduzido. } \\
\text { Relação de hierarquia e autoridade } \\
\text { vertical: professor e depois o aluno. } \\
\text { Responsável por manter a disciplina do } \\
\text { lugar e direcionar todas as ações. } \\
\text { ANDRAGOGIA: Ambiente de } \\
\text { aprendizagem cooperativo. } \\
\text { Relação de horizontalidade entre } \\
\text { pedagogo e aluno. Sem hierarquia mas } \\
\text { com respeito mútuo. } \\
\text { HEUTAGOGIA: Ambiente de } \\
\text { aprendizagem auto conduzido. A } \\
\text { atuação do pedagogo se restringe a } \\
\text { realizar suporte necessário quando } \\
\text { solicitado. }\end{array}$ \\
\hline
\end{tabular}

Fonte: Própria

\section{CONSIDERAÇÕES FINAIS}

Foi possível observar, ao longo desta revisão, que os pressupostos que devem ser assumidos nas práticas de ensino com adultos são diferentes de quando o trabalho é realizado com crianças. Os adultos tendem a ser mais independentes em seu processo de aprendizagem.

$\mathrm{Na}$ pedagogia o professor define o conteúdo que deve e como deve ser aprendido, na Andragogia, o que deve ser aprendido e definido pelo Facilitador e de que forma será aprendido é definido pelo aluno. Já na Heutagogia, quem determina essas duas fases do aprendizado são os próprios discentes, num processo em que eles, sozinhos, buscam e absorvem o conhecimento.

Nos modelos de aprendizagem analisados por esta pesquisa, o pedagogo possui funções distintas, exigindo deste profissional que esteja capacitado para atender todas as especificidades que se apresentarem. Isto constitui um grande 
desafio pois sua formação possui limitações em vários aspectos, fazendo com que o mesmo tenha que recorrer à formação continuada para aumentar seu nível de conhecimento e aprimorar suas habilidades.

Dessa forma os desafios enfrentados pelos pedagogos, nessa multiforme atuação profissional, são muitos e requerem além da vontade de ensinar o desejo de renovar o seu aprendizado, sendo o próprio pedagogo um aprendiz e um ser reflexivo no que tange a sua práxis diária, tendo ciência de sua responsabilidade no processo de ensino aprendizagem dos estudantes e lembrando que suas ações reverberarão nos resultados do sistema educacional como um todo.

\section{REFERÊNCIAS}

ABED / SEBRAE - Ecologia do Conhecimento. Disponível em: http://webcast4.isat.com.br/Player/Player.asp?Palestra ID=1252. Acesso em: 04 jan. 2014.

ALMEIDA, Maria Elizabeth Bianconcini de. As teorias principais da andragogia e heutagogia in LITTO et. al. Educação à distância: o estado da arte. São Paulo: Prentice Hall, 2009. p.105-111.

BELLAN, Zezina. Andragogia em ação: como ensinar adultos sem se tornar maçante. Santa Bárbara D'Oste, SP: Z3 Editora, 2005.

Heutagogia - Aprenda a Aprender Mais e Melhor. São Paulo: Socep.

CADINHA, Márcia Alvim. Conceituando Pedagogia e Contextualizando Pedagogia Empresarial. In: LOPES, TRINDADE, CADINHA. Pedagogia Empresarial: formas e contextos de atuação. 3 Ed. Rio de Janeiro: Wak, 2009. p. 15-38.

CALDEIRA, Ana Cristina Muscas. Avaliação da Aprendizagem em Meios Digitais: Novos Contextos. In: CONGRESSO INTERNACIONAL DE EDUCAÇÃ̃O A DISTÂNCIA, 11, 2004, Salvador-BA. Disponível em: http://www.abed.org.br/congresso2004/por/htm/033-TC-A4.htm. Acesso em: $7 \mathrm{dez}$ 2012.

CHESBRO, Steven, DAVIS, Lori. Applying Knowles' Model of andragogy to individualized osteoporosis education. Journal of Geriatric Physical Therapy, Vol.25;2:02. 2002. 
COSTA, Kemle Semerente. Práticas Educativas em Obesidade e Envelhecimento Desenvolvidas por Profissionais de Saúde de Goiânia: Significados e Desafios. Dissertação (mestrado). Convênio centro-oeste (UnB, UFG, UFMS). Programa Multiinstitucional em Ciências da Saúde. Goiânia, 2005.

CONAWAY, Wendy. Andragogy: Does one size fit all? A study to determine the applicability of andragogical principles to adult learners of all ages (2009). Walden Dissertations and Doctoral. In: https://scholarworks.waldenu.edu/dissertations/692/. Acesso: $15 / 05 / 2021$

FRANCO, Maria Amélia Santoro. A pedagogia para além dos confrontos. In: FÓRUM DE EDUCAÇÃO: PEDAGOGO, QUE PROFISSIONAL É ESSE? Belo Horizonte, 2002. Anais. Belo Horizonte: FUMEC, PUC-MG, UEMG, 125 p. (Parte IConferências).

GADOTTI, M. Perspectivas atuais da educação. Porto Alegre: Ed. Artes Médicas, 2000.

GIL, Antonio Carlos. Didática do Ensino Superior. São Paulo: Atlas, 2011.

GUIA do Estudante. Orientação Profissional: Pedagogia. Por redação, atualizado em 22 maio 2019, 17n39 - Publicado em 10 Junho 2012, 01 h48

https://guiadoestudante.abril.com.br/profissoes/pedagogia/. Acesso: 15/05/2021.

GOMES, Rita de Cássia Guarezi; PEZZI, Silvana e BÁRCIA, Ricardo Miranda. Tecnologia e Andragogia: aliadas na educação a distância Tema: Gestão de Sistemas de Educação a Distância. 2006. Disponível em http://www.abed.org.br/publique/cgi/cgilua.exe/sys/start.htm?infoid=121\&sid=121\&Us erActiveTemplate=4abed Acesso em 27/05/2006. Acesso em 03 nov. 2013.

KENYON, Chris; HASE, Stewart. Moving from andragogy to heutagogy in vocation education. Disponível em: $<$ http/www. avetra.org.au/abstracts and papers 2000/HaseKenyon full.pdf> Acesso em: 10 jun. 2016

KNOWLES. Malcolm, S.; HOLTON III. Elwood F.; SWANSON. Richard A. Aprendizagem de resultados: uma abordagem prática para aumentar a efetividade da educação corporativa. Rio de Janeiro: Campus, 2009.

LAKATOS, Eva Maria, MARCONI, Marina de Andrade. Fundamentos de Metodologia Científica. 3 Ed. Ver. e ampl. São Paulo: Atlas, 1993.

LIBÂNEO, José Carlos. Pedagogia e pedagogos: inquietações e buscas. Educar. n. 17. p. 153-176. Editora da UFPR. Curitiba, 2001. 
Que destino os educadores darão à Pedagogia? IN: PIMENTA, Selma Garrido (Org.). Pedagogia, ciência da educação?. São Paulo: Cortez. 1996.

LITTO, Fredric M.; FORMIGA, Manuel M. Educação à distância: o estado da arte. São Paulo: Pearson Education do Brasil, 2009.

LOPES, Marcos Levi. Autodeterminação no esporte: $O$ modelo dialético da motivação intrínseca e extrínseca- Tese (doutorado). Escola de Educação Física. UFRGS. Porto Alegre, 2011.

NOGUEIRA, Sonia Mairos. A andragogia: que contributos para a prática educativa? Linhas. Vol. 5, N.2. Florianópolis, 2004.

HOLTON, Elwood; SWANSON, Richard. Andragogy in Practice: Clarifying the Andragogical Model of Adult Learning. Performance Improvement Quarterly, 14(1) pp. 118-143. 2001.

MARQUES, Francisca Maria Mendes. Andragogia: Sonho e Realidade. UNAR, Araras (SP), v.1, n.1, p.76-78, 2007.

MADEIRA, Vicente de Paulo Carvalho. Para falar em Andragogia. Educação do Trabalhador, v. 2, CNI-SESI. 1999.

MEIRIEU, Philippe. A Pedagogia entre o Dizer e o Fazer: a coragem de começar. Porto Alegre, Artmed, 2002.

OLIVEIRA, Ari Batista de. Andragogia, facilitando a aprendizagem. Educação do Trabalhador, v. 3, CNI-SESI. 1999.

RIBEIRO, A. E. do A. Pedagogia empresarial: atuação do pedagogo na empresa. Rio de Janeiro: Wak, 2008.

ROGERS, Jenny. Aprendizagem de Adultos: fundamentos para Educação Corporativa. Porto Alegre: Artmed, 5 Ed - 2011.

SANTOS, Daniela. Revisão da literatura: educação à distância. Administradores.com, 2008. Disponível em: <http://www.administradores.com. br/artigos/revisao_da_literatura_educacao_a_distancia/20823>. Acesso em: 12 dez. 2013.

SAVIANI, Dermeval. Pedagogia: o espaço da Educação na Universidade. Cadernos de Pesquisa, v. 37. N. 130, p. 99-134, jan./abr. 2007.

SILVA, Carmem Silva Bissolli da. Curso de pedagogia no Brasil: História e identidade. Campinas, SP: Autores Associados, 1999. 


\section{CRIAR EDUCAÇÃO}

Revista do Programa de Pós-Graduação em Educação - UNESC

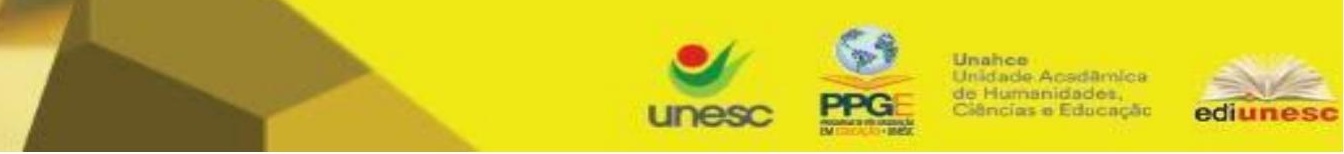

Criar Educação, Criciúma, v. 9, nำ1, jan/jul 2021.- PPGE - UNESC - ISSN 2317-2452

VEIGA, Ilma Passos Alencastro. Aventura de formar professores. Campinas: Papirus, 2009.

VOGT, Maria S. Loki; ALVES, Elioenai D. Revisão teórica sobre a educação de adultos para a aproximação com a andragogia. Revista Educação (UFSM) v.30, n. 2, jul./dez. 200 In: https://periodicos.ufsm.br/reveducacao/article/view/3746/2150 Acesso: 15/05/2021.

Recebido outubro de 2020

Aprovado abril de 2021 